Research Article

\title{
Synthesis, Characterization, and Antibacterial Evaluation of Heteroleptic Oxytetracycline-Salicylaldehyde Complexes
}

\author{
Rohit Kumar Dev $\mathbb{D}^{1},{ }^{1}$ Parashuram Mishra $\mathbb{D}^{1},{ }^{1}$ Narendra Kumar Chaudhary $\mathbb{D}^{1,2}$ \\ and Ajaya Bhattarai $\mathbb{D}^{2}$ \\ ${ }^{1}$ Bio-inorganic and Materials Chemistry Research Laboratory, Mahendra Morang Adarsh Multiple Campus, \\ Tribhuvan University, Biratnagar, Nepal \\ ${ }^{2}$ Department of Chemistry, Mahendra Morang Adarsh Multiple Campus, Tribhuvan University, Biratnagar, Nepal
}

Correspondence should be addressed to Ajaya Bhattarai; bkajaya@yahoo.com

Received 7 April 2020; Revised 9 June 2020; Accepted 3 July 2020; Published 30 July 2020

Academic Editor: Nenad Ignjatović

Copyright (c) 2020 Rohit Kumar Dev et al. This is an open access article distributed under the Creative Commons Attribution License, which permits unrestricted use, distribution, and reproduction in any medium, provided the original work is properly cited.

\begin{abstract}
A new series of mixed ligand complexes of $\mathrm{Cd}(\mathrm{II})$ and $\mathrm{Mo}(\mathrm{V})$ were successfully synthesized by refluxing the mixture solution of oxytetracycline hydrochloride (OTC.HCl) with an aqueous and alcoholic solution of metal $(\mathrm{M}=\mathrm{Cd}(\mathrm{II})$ and $\mathrm{Mo}(\mathrm{V}))$ salts and an alcoholic solution of salicylaldehyde (Sal). The complexes were characterized by modern analytical and spectral methods such as elemental microanalysis, $\mathrm{pH}$, conductivity, surface tension, viscosity, melting point, and spectral methods such as FT-IR, NMR, electronic absorption, SEM, and mass spectrometry. Conductivity measurements of the complexes revealed their electrolytic nature. The kinetic and thermal stabilities were investigated using thermogravimetric and differential thermal analysis techniques. Thermodynamic and kinetic parameters such as $E^{*}, \Delta H^{*}, \Delta S^{*}$, and $\Delta G^{*}$ were calculated from TG curves using the Coats-Redfern method. Geometry optimization of the proposed structure of the complexes was achieved by running MM2 calculations in a Gaussian-supported CS ChemOffice 3D Pro.12.0 version software. The final optimized geometrical energies for respective CdOTC/Sal and Mo-OTC/Sal complexes were found to be 923.1740 and $899.3184 \mathrm{kcal} / \mathrm{mol}$. The electronic absorption spectral study revealed a tetrahedral geometry for the Cd-OTC/Sal complex and octahedral geometry for the Mo-OTC/Sal complex. The antibacterial sensitivity of the complexes was evaluated against three bacterial pathogens such as S. aureus, E. coli, and P. mirabilis using the modified Kirby-Bauer paper disc diffusion method. The antibacterial study revealed significant growth inhibitory action of the complexes.
\end{abstract}

\section{Introduction}

The current interest in the improvement of the functionality and applicability of metal complexes has become an important part of coordination chemistry research [1, 2]. Coordination compounds containing metals bound in the mesh of ligands have a variety of biological functions because many of them are used in the treatment of diseases in medical science [3]. Besides their biological functions, they are also used in chemical sciences as catalysts [4], reaction templates, and reaction activators [5]. The chief process for the fabrication of metal complexes is redox chemistry, where the metals provide a vacant orbital to the ligand for chelation. The ligand functions as an electron donor and behaves as a Lewis base. The formation of the complex is therefore a simple Lewis acid-base reaction [6]. We have focused our research intended to address the antibacterial significance of the metal complexes of the oxytetracyclinesalicylaldehyde mixed ligand. Recently, antibiotic discovery has become a critical issue in pharmaceutical science due to the increased risk of drug resistance [7, 8]. Medical science has established antibiotic therapy for the treatment of bacterial pathogens, and antibiotics are now considered one of the core drugs of modern medicine. Over the past few decades, these drugs have been losing their foundation in fighting bacteria. The bacterial strains are changing genomic characters by mutation process, and they are no longer affected by used antibiotics that once suppress their growth 
and activity [9]. Several natural antibiotics have lost their activity, and we need to synthesize laboratory-based antibiotics to overcome the antibiotic resistance crisis. Therefore, it can be considered a better option to control disease outbreaks by metal-based drugs in an effective way $[10,11]$. In this research study, the ligands used for heteroleptic complex formation are oxytetracycline and salicylaldehyde.

Oxytetracycline is a broad-spectrum antibiotic of the class tetracycline that performs antibiotic functions by inhibiting protein synthesis in bacteria. It was first isolated from the soil bacteria Streptomyces rimosus in 1948, patented in 1949, and came into commercial use in 1950 [12]. It stands parallel in properties to tetracycline, which is commonly used as a veterinary antibiotic. In humans, it is used to treat eye infection trachoma, genital infection, urethritis, chest infection, psittacosis, and pneumonia. As a veterinary medicine, oxytetracycline is used for the treatment of infections in animal husbandry and fish farming $[13,14]$, in agriculture as a pesticide, and as a dietary supplement for livestock [15]. In the past few decades, its use as an antibiotic has become less common due to increased antibacterial resistance among targeted pathogens. Structurally, oxytetracycline (Figure 1) has a naphthacene ring skeleton similar to tetracycline, with many chromophoric groups responsible for metal attachment in complex formation. It is a type II bacterial aromatic polyketide containing one aromatic ring. There is a structural difference between tetracycline and the presence of a substituent group - $\mathrm{OH}$ at the $\mathrm{C} 5$ of ring $\mathrm{B}$ [16]. This makes a vast difference in the physiological and biological profiles of the compounds. In a survey of its toxic profile, oxytetracycline can complex with $\mathrm{Ca}$ and $\mathrm{Mg}$ in vivo in the human body and cause severe physiological defects $[17,18]$. Besides the in vivo physiological defects, it can also eliminate toxic heavy metals from the human body by complex formation processes. Almost $50-80 \%$ oxytetracycline undergoes excretion in its in vivo use in humans and animals because of its poorly absorbing nature. Therefore, the metal interaction chemistry of oxytetracycline can be considered an important part of research to standardize its physical and biological profiles.

For the continuation of our ongoing antibiotic research, this work focused on the synthesis of heteroleptic complexes using oxytetracycline and salicylaldehyde along with metal salts. The complexation behavior was investigated by physicochemical studies such as melting point, conductivity, $\mathrm{pH}$, surface tension, viscosity, and density measurements. Their structural characterization was further investigated by spectroscopic studies such as electronic absorption, FT-IR, NMR, and ESI-MS. The surface morphology by SEM study and thermal stability by TGA/DTA study were performed to parameterize the complexes. The complexes were screened for their in vitro antibacterial susceptibility tests with three clinical pathogens to show their biological significance.

\section{Experimental}

2.1. Materials and Reagents. All chemicals and reagents which were used in the research were of analytical reagent grade (AR) with the highest purity. The chemicals were purchased from various chemical agencies and included oxytetracycline hydrochloride (TCI), salicylaldehyde (Loba Chemie Pvt., Ltd.), $\mathrm{CdCl}_{2} \cdot \mathrm{H}_{2} \mathrm{O}$ (Loba Chemie Pvt., Ltd.), molybdenum (V) chloride (Sigma-Aldrich), and MHA (Himedia). Distilled ethanol was used for the synthesis. The glassware used in the research was a high-grade borosilicate type to provide overall performance and extreme precision. Double-distilled water was used to wash the equipment.

2.2. Instrumentation. The $\mathrm{C}, \mathrm{H}$, and $\mathrm{N}$ contents of the complexes were recorded using a Euro-E 3000 microanalyzer. Conductivity measurements were done at $25^{\circ} \mathrm{C}$ in DMSO solvent using an auto-ranging/TDS meter TCM 15+ digital conductivity meter. The VEEGO ASD-10013 programable apparatus was used to record the melting point of the complex. At $25^{\circ} \mathrm{C} \pm 0.1^{\circ} \mathrm{C}$, the $\mathrm{pH}$ measurement was calculated using a digital pH meter AN ISO 9001: 2008 certified company instrument. Using the ring detachment technique, surface tension was measured using the help of Kruss K20S Easy Dyne Force Tensiometer. A PerkinElmer Spectrum II instrument was used to record the FT-IR spectra using $\mathrm{KBr}$ pellets in the wavenumber between 400 and $4000 \mathrm{~cm}^{-1}$. At room temperature, NMR spectra were recorded from Bruker AvII- $400 \mathrm{MHz}$ spectrometer using the solvent DMSO- $\mathrm{d}_{6}$ and TMS (tetramethylsilane) as the reference standard. UV/Vis spectral bands at $10^{-3} \mathrm{M}$ concentration in DMSO were calculated using an instrument called Varian Cary 5000 in the range of 200 to $1000 \mathrm{~nm}$. ESI-MS spectrometry technique is applied to record the mass spectra by using a water UPLC-TQD mass spectrometer. A PerkinElmer Diamond TG/DTA instrument was used to evaluate the thermal and kinetic properties of the complexes at room temperature to $1000^{\circ} \mathrm{C}$ under a nitrogen atmosphere with a linear heating rate of $10^{\circ} \mathrm{C} / \mathrm{min}$. A JEOL JSM-6390LV scanning electron microscope instrument was used to detect the surface morphology. The geometry optimization of the complexes was done with the help of $3 \mathrm{D}$ modeling via Chem3D Pro.12.0 software.

2.3. Synthesis of Complexes. The metal complexes Cd-OTC/ Sal and Mo-OTC/Sal were prepared by heating the mixture solution of $20 \mathrm{ml}$ oxytetracycline hydrochloride $(0.9941 \mathrm{~g}$, $2 \mathrm{mmol}$ ) in ethanol with $10 \mathrm{ml}$ aqueous solution of $\mathrm{CdCl}_{2} \cdot \mathrm{H}_{2} \mathrm{O}(0.4029 \mathrm{~g}, 2 \mathrm{mmol}) / 10 \mathrm{ml}$ alcoholic solution of $\mathrm{MoCl}_{5}(0.5469 \mathrm{~g}, 2 \mathrm{mmol})$. To this solution, $0.2 \mathrm{ml}$ of salicylaldehyde $(2 \mathrm{mmol})$ was added and refluxed for $8 \mathrm{~h}$. Ammonia solution was added dropwise to maintain a $\mathrm{pH}$ of 7. Under these conditions, precipitation of the complexes was formed and filtered, then washed with ethanol, and finally dried under vacuum desiccators over anhydrous $\mathrm{CaCl}_{2}$. The precipitate was then kept in an airtight vial for further use. The synthetic route for the metal complexes is shown in Scheme 1.

Cd-OTC/Sal: yield (75\%). Color: gray, M.pt. $>260^{\circ} \mathrm{C}$, anal. $\mathrm{C}_{29} \mathrm{H}_{28} \mathrm{CdN}_{2} \mathrm{O}_{11}$ (692.95): calcd. C 50.26, $\mathrm{H} 4.07, \mathrm{~N}$ 4.04, O 25.40; Cd 16.22; found C 50.20, H 4.26, N 4.36, O 25.33, Cd 16.22. IR (KBr pellet, selected bands): $\overline{\mathrm{U}}_{\max }=3432$ (b, O-H/N-H str.), 1599 (s, C=O str.), 1501 (aromatic, C=C str.), 1452 (C-N), 1178 (C-O), 595 (M-O), 503 (M-N). UV/ 


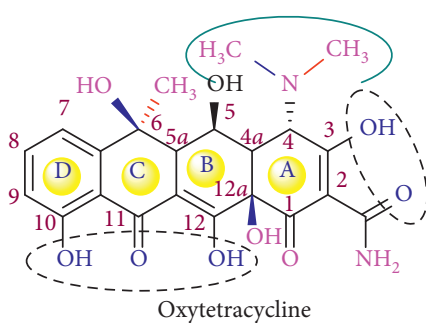

(a)

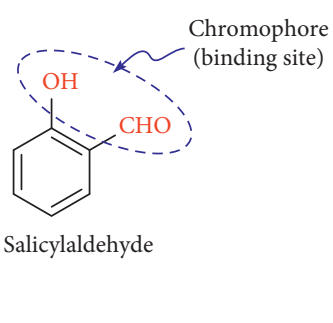

(b)

FIgURE 1: Structure of (a) oxytetracycline and (b) salicylaldehyde.
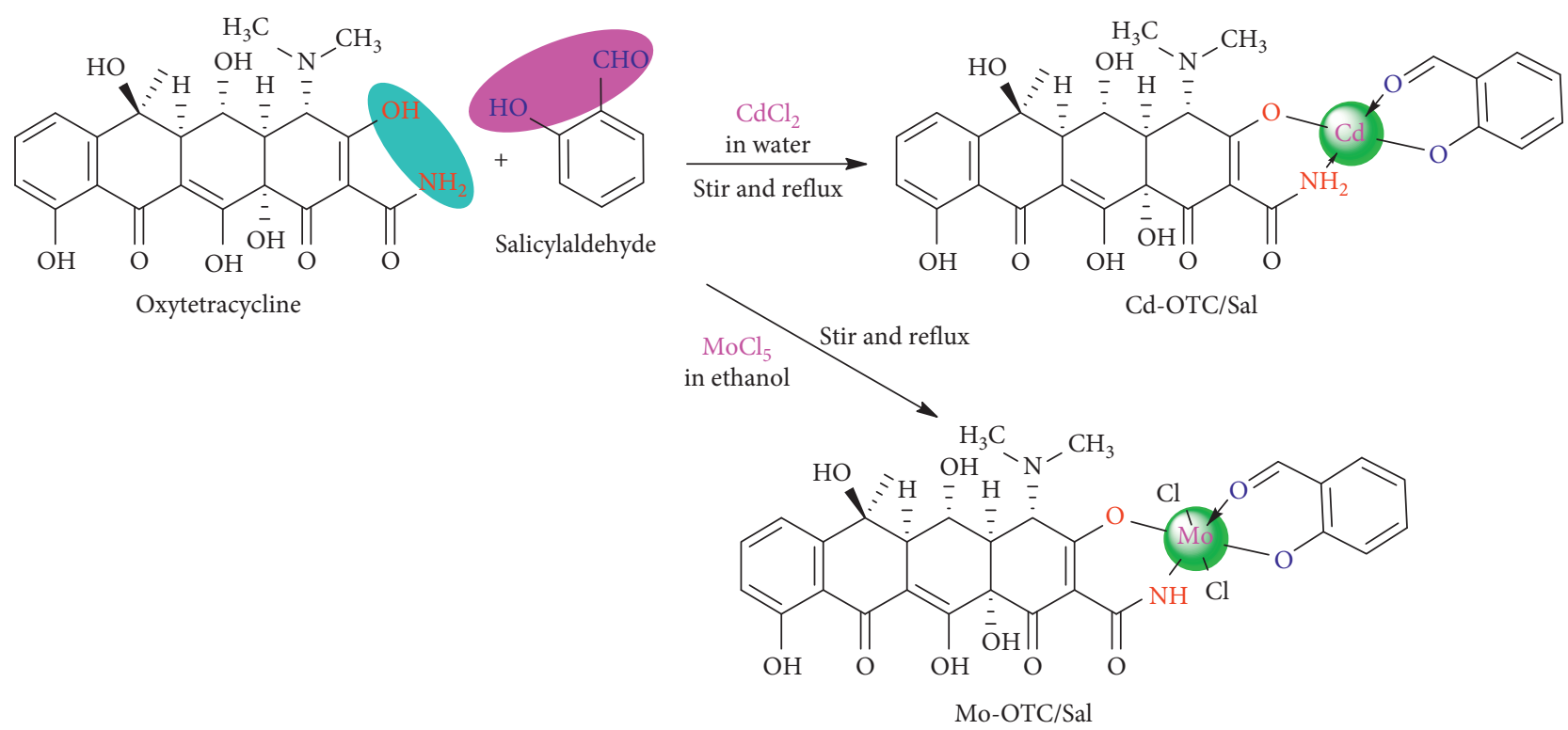

Scheme 1: Synthetic route for $\mathrm{Cd}(\mathrm{II})$ and $\mathrm{Mo}(\mathrm{V})$ metal complexes.

Vis: $\lambda_{\max }=267,322,375 \mathrm{~nm}$. ESI-MS, positive: $\mathrm{m} / z=693$ $[\mathrm{M}+\mathrm{H}]^{+}$. Conductivity: $\Lambda_{\mathrm{M}}=23.33(\mu \mathrm{S} / \mathrm{cm}), \mathrm{pH}=7.42$, density $=0.954(\mathrm{gm} / \mathrm{ml})$, surface tension $=61.80(\mathrm{mN} / \mathrm{m})$, viscosity $=20.74(\mathrm{cp})$.

Mo-OTC/Sal: yield (65\%). Color: brown, M.pt. $>260^{\circ} \mathrm{C}$, anal. $\mathrm{C}_{29} \mathrm{H}_{27} \mathrm{Cl}_{2} \mathrm{MoN}_{2} \mathrm{O}_{11}$ (747.41): calcd. C 46.60, $\mathrm{H} 3.78, \mathrm{~N}$ 3.75, O 23.55, Cl 9.49, Mo 12.84; found C 46.59, H 3.77, N 3.74, O 23.54, Cl 9.48, Mo 12.83. IR ( $\mathrm{KBr}$ pellet, selected bands): $\overline{\mathrm{U}}_{\max }=3437$ (b, O-H/N-H str.), 1628 (s, C=O str.), 1546 (aromatic, C=C str.), $1456(\mathrm{C}-\mathrm{N}), 1164(\mathrm{C}-\mathrm{O}), 517$ (MO), $463(\mathrm{M}-\mathrm{N})$. UV/Vis: $\lambda_{\max }=264,318 \mathrm{~nm}$. ESI-MS, positive: $m / z=747.41[\mathrm{M}+\mathrm{H}]^{+}$. Conductivity: $\Lambda_{\mathrm{M}}=243.40(\mu \mathrm{S} /$ $\mathrm{cm}), \quad \mathrm{pH}=4.84, \quad$ density $=0.976 \quad(\mathrm{gm} / \mathrm{ml})$, surface tension $=60.50(\mathrm{mN} / \mathrm{m})$, viscosity $=21.03(\mathrm{cp})$.

2.4. Antibacterial Assessment. The synthesized metal complexes were tested for their in vitro antimicrobial assessment which was done at the Microbiology Laboratory of MMAM Campus, Tribhuvan University, Biratnagar. The tests were performed by modified Kirby-Bauer paper disc diffusion on three pathogens: S.aureus (Gram-positive) and E. coli and $P$ mirabilis (Gram-negative). The culture of bacteria was revived by inoculating the organism in freshly prepared nutrient agar and kept in an incubator at $37^{\circ} \mathrm{C}$ for a few hours for complete growth. For the tests, test solutions were prepared by dissolving the synthesized complexes in 30\% DMSO at three different concentrations $(50,25$, and $12.5 \mu \mathrm{g} / \mu \mathrm{L})$ and blank paper discs of $5 \mathrm{~mm}$ diameter size with Whatman No. 1 filter paper cut by a punching machine and sterilized in an autoclave. The MHA media was prepared in an autoclave and solidified on Petri discs under UV laminar flow to decrease bacterial contamination. The fresh revived bacterial culture was spread on the solidified MHA media, and blank sterilized discs were also seeded and loaded with $10 \mu \mathrm{L}$ test compounds under UV laminar flow to decrease their bacterial contamination. One blank disc soaked with DMSO acted as a solvent control while another amikacin $(30 \mu \mathrm{g} / \mathrm{disc})$ acted as a positive control to compare the effectiveness of the tested compounds. After performing all these tasks, the loaded Petri plates were placed in an incubator for up to $24 \mathrm{~h}$ at $37^{\circ} \mathrm{C}$ to note the diameter of the zone of inhibition measured by the help of the antibiogram zone measuring scale $[19,20]$.

\section{Results and Discussion}

3.1. Physical Characterization. In the present study, the structure of metal complexes was characterized by various physicochemical and spectroscopic techniques. At room temperature, the complexes are colored solid, moisture-free, 
and air-stable and have greater melting points. All the complexes were soluble in DMSO and DMF, but insoluble in water. The complexes were stored in an airtight vial and kept in vacuum desiccators under anhydrous $\mathrm{CaCl}_{2}$. The change in the color of the ligand up to complex formation is the result of the complexation of the ligand with metal ions, which is further supported by $\mathrm{pH}$, conductivity, surface tension, density, viscosity, and melting point. The TGA/ DTA and electronic absorption denote better results of the calculated value and conclude a better relationship with the proposed structure.

\subsection{Spectroscopic Characterization}

3.2.1. FT-IR Spectral Study. Characteristic IR bands for the metal complexes and their assignments are presented in Figures 2 and S1. The FT-IR spectra of the Cd-OTC/Sal and Mo-OTC/Sal metal complexes showed characteristic bands at $3432 \mathrm{~cm}^{-1}$ and $3437 \mathrm{~cm}^{-1}$, which may be assigned to the $v(\mathrm{OH} / \mathrm{NH})$ stretching vibration $[21,22]$. Similarly, the $-\mathrm{CH}_{3}$ stretching vibrations appeared at $2924 \mathrm{~cm}^{-1}$ and $2928 \mathrm{~cm}^{-1}$ region [23, 24]. The strong intensity bands at $1599 \mathrm{~cm}^{-1}$ and $1628 \mathrm{~cm}^{-1}$ are due to the carbonyl $(\mathrm{C}=\mathrm{O})$ group band, which partially overlaps the $\mathrm{N}-\mathrm{H}$ band appearing as a small doublet $[25,26]$. A band corresponding to the $v(\mathrm{C}-\mathrm{N})$ stretch appeared at $1452 \mathrm{~cm}^{-1}$ and $1456 \mathrm{~cm}^{-1}$ and was displaced by coordination with the metallic center. Such behavior of a band was also found in the literature [27]. At a lower frequency level, the metal complexes show bands at $595 \mathrm{~cm}^{-1} \&$ $517 \mathrm{~cm}^{-1}$ and $503 \mathrm{~cm}^{-1} \& 463 \mathrm{~cm}^{-1}$, which may be due to the $v(\mathrm{M}-\mathrm{O})$ and $v(\mathrm{M}-\mathrm{N})$ coordination modes, respectively $[28,29]$.

3.2.2. ${ }^{1} H-N M R$ Spectral Study. For further confirmation of the binding mode of metal ions in the complexes, the ${ }^{1} \mathrm{H}$ NMR spectrum in DMSO- $\mathrm{d}_{6}$ solvent was carried out at room temperature using TMS (tetramethylsilane) as a reference standard. The chemical shifts $(\delta)$ are measured in ppm units present in the downfield from TMS [30, 31]. The ${ }^{1} \mathrm{H}-\mathrm{NMR}$ spectra of the metal complexes are presented in Figures S2 and S3, and the spectral data are presented in Table S1. The Cd-OTC/Sal showed spectral peaks at $6.889-7.355 \mathrm{ppm}$, attributed to aromatic protons. These aromatic protons are slightly moved up-field and support their coordination of ligands with metal ions [32]. The peaks in the region of 4.284-4.397 ppm suggest the peak for the - $\mathrm{NH}$ group [33]. A singlet peak at $1.670 \mathrm{ppm}$ in the spectra of the metal complex was assigned to the methyl protons. Similarly, the peaks at $2.370-2.553 \mathrm{ppm}$ are assigned to methylene protons [31]. The Mo-OTC/Sal complex shows a multiplet peak at 7.186-7.205 ppm, assignable to aromatic protons [34]. The peak at $1.047-1.082 \mathrm{ppm}$ is due to a methyl group and a singlet peak at $2.551 \mathrm{ppm}$ is assigned to methylene protons [35]. Each hydrogen of the aromatic ring observed one distinct peak at $4.414 \mathrm{ppm}$ [36]. Hence, the values in the peaks show good agreement with the proposed structure of the metal complexes.
3.2.3. Mass Spectral Study. The ESI mass spectrometry is an instrumental technique for determining the molecular mass of compounds. It helps to determine the composition and purity of the compounds. The mass spectrum provides information about the stoichiometric compositions of the compounds. In our study, the mass spectral peaks at $\mathrm{m} / z 693$ and $747.41 \mathrm{amu}$ for the respective Cd-OTC/Sal and MoOTC/Sal complexes are assigned to the molecular ion peak $[\mathrm{M}+\mathrm{H}]^{+}$, and their corresponding base peaks are at $\mathrm{m} /$ $z=461$ and $m / z=616$, which signify the proposed molecular formula of the complex [37, 38]. Besides the molecular ion peak, there are additional peaks called fragment peaks formed by fragmentation of molecular ion peaks and lie in the region at $m / z 690,620,543,483,385$, and 300 in the CdOTC/Sal complex, and at $\mathrm{m} / z$ 743, 728, 723, 709, 674, 640, 537,473 , and 450, respectively, in the Mo-OTC/Sal complex. The ESI-MS spectra are presented in Figures 3 and S4.

3.2.4. Electronic Absorption Spectral Study. The important electronic absorption spectral bands for metal complexes were recorded in the $250-800 \mathrm{~nm}$ ranges of wavelength at room temperature in DMSO solvents taking the same solvents as the blank [30]. Electronic absorption spectroscopy is an analytical instrumental tool for determining the characterization and identification of binding modes for compounds. The metal complex of Cd-OTC/Sal shows peaks at 267, 322, and 375 may be due to $\pi \longrightarrow \pi^{*}, n \longrightarrow \pi^{*}$ transitions. The electronic configuration of the Cd(II) metal complex was $d^{10}$, which signifies the absence of any $d-d$ electronic transition and the bands attributed to the CT (charge transition), compatible with tetrahedral geometry; hence, their absorption band spectra contain red and blue shifts with hyperchromic effect ions [21, 38]. In the same way, the metal complexes of Mo-OTC/Sal showed peaks at 264 and $318 \mathrm{~nm}$, signifying the $\pi \longrightarrow \pi^{*}$ and $n \longrightarrow \pi^{*}$ transitions due to the $-\mathrm{C}=\mathrm{N}$ - and $-\mathrm{C}=\mathrm{O}$ - groups in the ligand. Band $\sim 318$ is denoted as the characteristic band of the ligand. Since the complex is diamagnetic and has an octahedral geometry, it is assigned as a ligand-metal charge transfer existing from the HOMO of phenolic oxygen to the LUMO of the molybdenum $[39,40]$. All these bands are presented and assigned in Figure S5.

3.3. Thermal Study. TGA/DTA studies are used to determine the composition of materials and also to predict the thermal and kinetic stability of compounds. This analysis was done in the temperature range of $40^{\circ} \mathrm{C}$ to $860^{\circ} \mathrm{C}$ under a nitrogen atmosphere at a linear heating rate of $10^{\circ} \mathrm{C} / \mathrm{min}$. TGA/DTA is also an analytical instrumental technique that determines weight loss or gains due to various processes such as absorption, adsorption, sorption, or desorption of volatile components, decomposition, oxidation, and reduction reactions. The TGA curves help the scientist for profile structural information for new compounds having a coordination sphere. The initial decomposition steps in complexes are an endothermic process that denotes the loss of water molecules [41, 42]. 


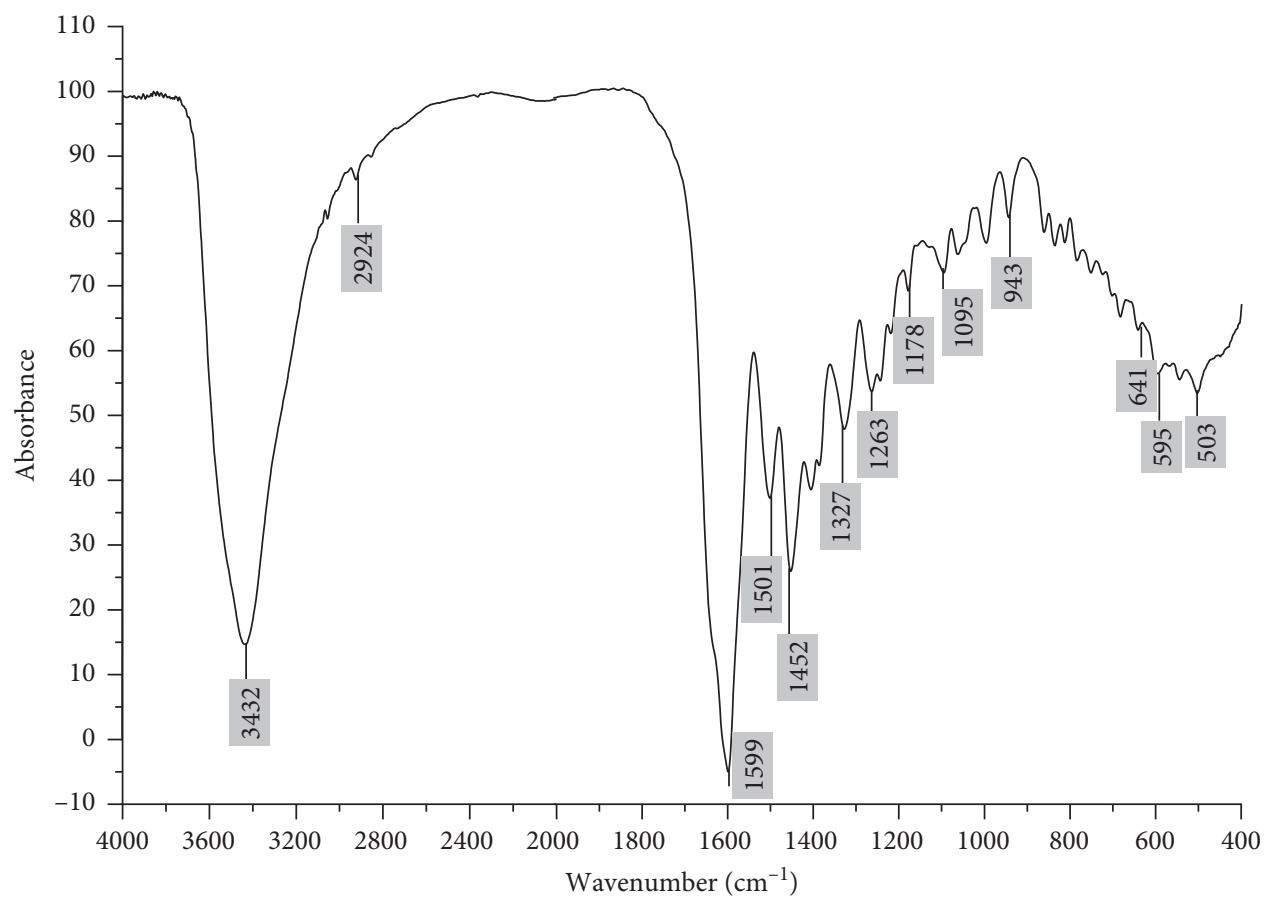

FIgURE 2: FT-IR spectrum of the Cd-OTC/Sal complex.

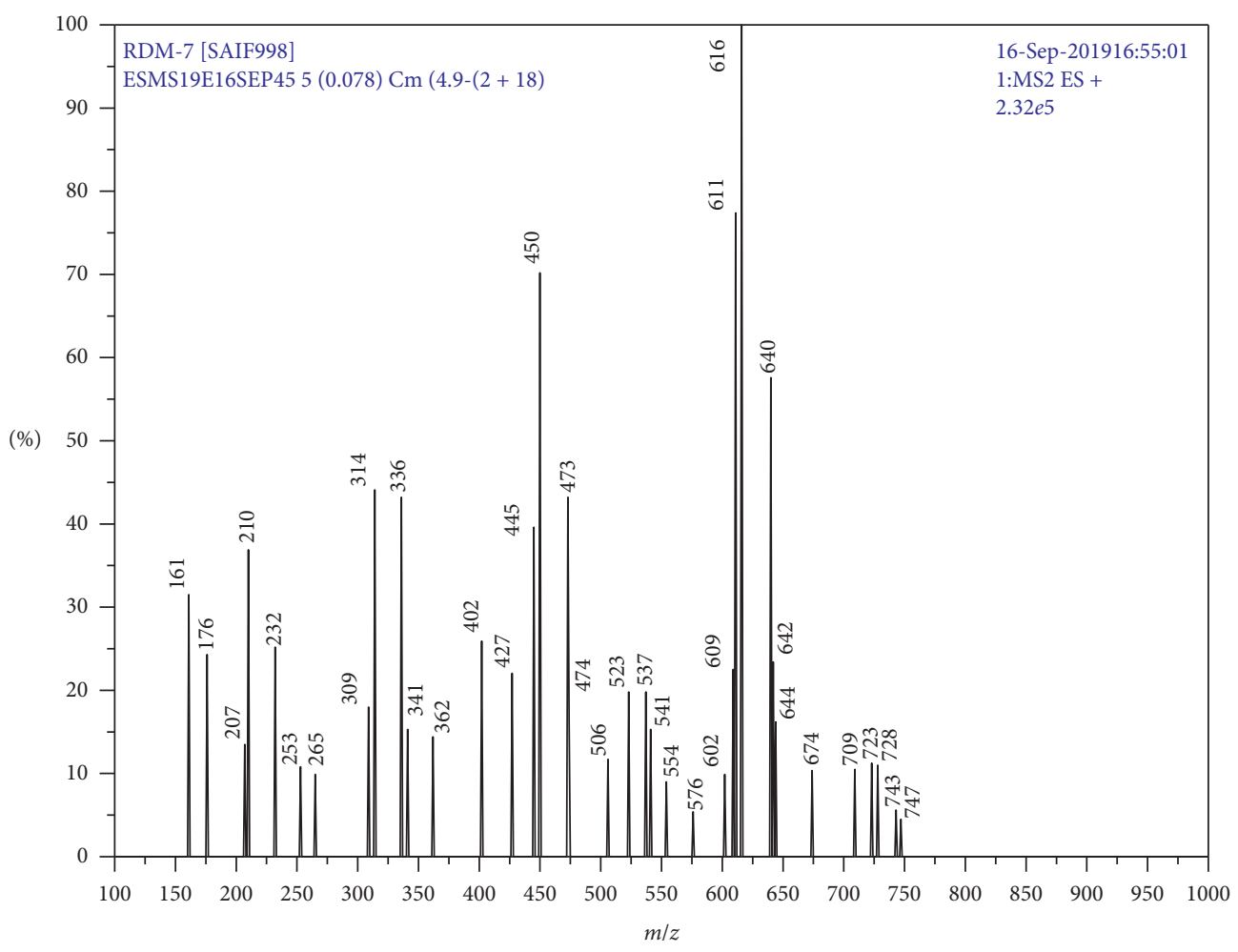

Figure 3: ESI-MS spectrum of the Mo-OTC/Sal complex.

The thermogram of the Cd-OTC/Sal metal complex showed decomposition at two steps between the temperature range of $362.05^{\circ} \mathrm{C}-680.76^{\circ} \mathrm{C}$. The weight loss of $28.01 \%$ $(-0.837 \mathrm{mg})$ occurred in the first decomposition step in the temperature range of $362.05^{\circ} \mathrm{C}-448.12^{\circ} \mathrm{C}$. The second decomposition takes place with a weight loss of $9.58 \%$ $(-0.232 \mathrm{mg})$ within the temperature range of $611.13-680.76^{\circ} \mathrm{C}$. The last step of decomposition explains the complete loss of the ligand from the complex, leaving behind metal oxide $(\mathrm{CdO})$ as the end product. In the same way, the 
thermogram of the Mo-OTC/Sal showed decomposition in three steps between the temperature range of $374.30^{\circ} \mathrm{C}-508.22^{\circ} \mathrm{C}$. The weight loss of $13.022 \%(-0.742 \mathrm{mg})$ takes place in the first stage of decomposition at a temperature range of $374.30-397.33^{\circ} \mathrm{C}$. The mass losses of $17.39 \%(-0.548 \mathrm{mg})$ and $6.08 \%(-0.657)$ occurred in the second and third decomposition steps within the temperature ranges of $407.21-417.17^{\circ} \mathrm{C}$ and $464.40-508.22^{\circ} \mathrm{C}$. The final residue obtained during the decomposition stage is in the form of a metal oxide such as $\mathrm{Mo}_{2} \mathrm{O}_{5}$. The thermograms of the studied complexes are reported in Figures 4 and S6.

3.3.1. Kinetic Parameters. The thermodynamic and kinetic parameters of the complexes were obtained using the following Coats-Redfern relation:

$$
\ln \left[-\frac{\ln (1-\alpha)}{T^{2}}\right]=\ln \left[\frac{A R}{\beta E^{*}}\right]-\frac{E^{*}}{R T},
$$

where $T$ represents the temperature observed on the DTG curve, $A$ and $E^{*}$ denote the Arrhenius pre-exponential factor and activation energy, which can be calculated from the graphical process. $R$ denotes the universal gas constant and $\beta$ is the linear heating rate. Using the equation $y=m x+c$, a linear plot on the left-hand side vs. $1 / T$, whose slope $\left(-E^{*} / R\right)$ gives the activation energy. Similarly, other kinetic parameters such as the entropy of activation $\left(\Delta S^{*}\right)$, enthalpy of activation $\left(\Delta H^{*}\right)$, and free energy of activation $\left(\Delta G^{*}\right)$ were calculated using the following equations:

$$
\begin{aligned}
\Delta S^{*} & =R \ln \left[\frac{A h}{K_{B} T}\right], \\
\Delta H^{*} & =E^{*}-R T, \\
\Delta G^{*} & =\Delta H^{*}-T \Delta S^{*} .
\end{aligned}
$$

Here, various decomposition steps of the kinetic and thermodynamic parameters were calculated and are presented in Tables 1 and 2 [43]. All the complexes show greater values and reflect their high thermal stability because of their covalent bond character. In both complexes, all decomposition steps contain negative entropy of activation, which clearly shows a nonspontaneous dehydration reaction, and the positive values of $\Delta G^{*}$ of all decomposition stages for both complexes show nonspontaneous nature and $\Delta H^{*}$ is negative which indicates the exothermic process, and the correlation coefficient is shown in the graph indicating a better fit.

3.4. SEM Study. The coordination of metal with the ligand changes the metal complex surface morphology and was done by SEM (scanning electron microscopy) analysis. SEM is an important analytical instrumental technique for surface morphology. The micrograph shows the size, shape, ductility, strength, and arrangement of an object. The SEM micrograph of Cd-OTC/Sal metal complex (Figure 5(a)) exhibits microsphere-like morphology with aggregation of small nanoparticles, leading to the formation of a large

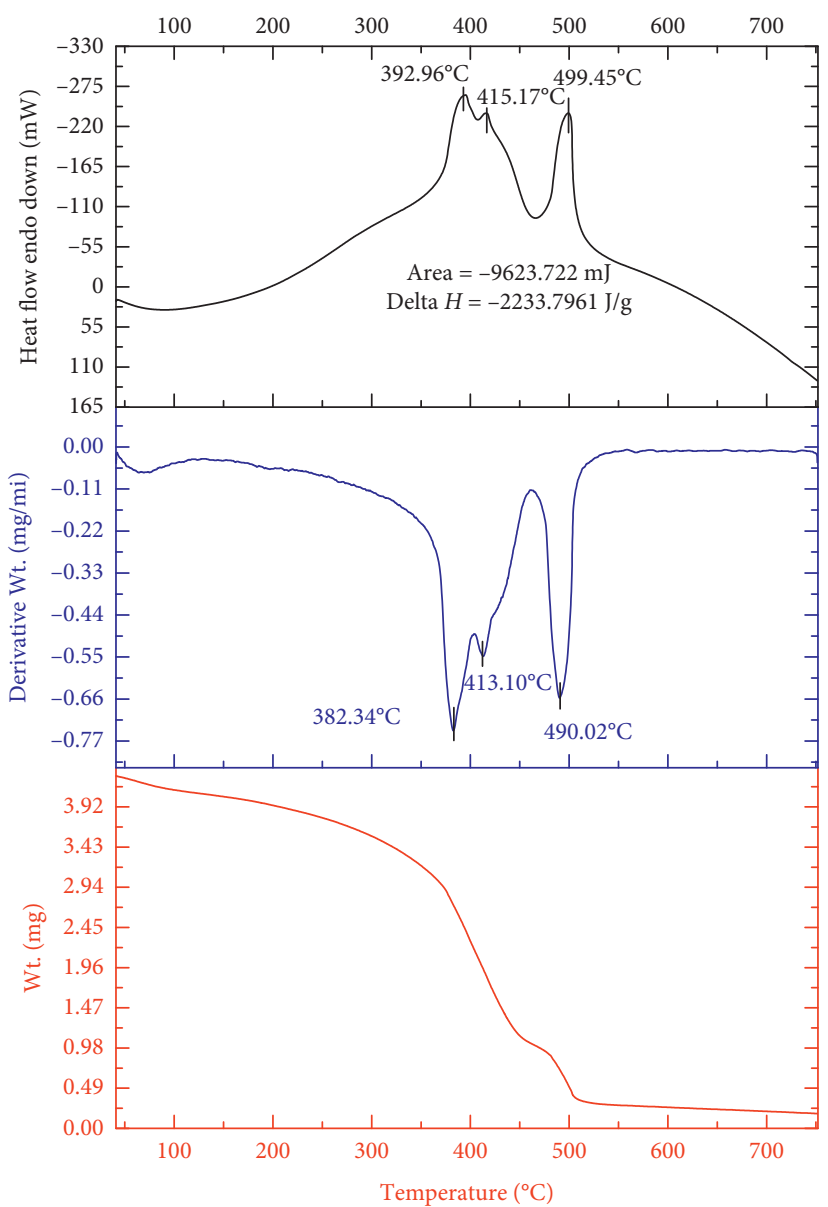

Figure 4: Thermogram of the Mo-OTC/Sal complex.

sphere. Similarly, Mo-OTC/Sal metal complex (Figure 5(b)) shows that the surface morphology is a spherical nanomaterial whose aggregation gives rise to an increase in the size of a large sphere [44-46], as presented in Figure 5.

3.5. Molecular Modeling Study. The synthesized complexes were geometrically analyzed and characterized by molecular simulation processed in CS ChemOffice 3D Pro.12.0 version software, which gives a better and more accurate assessment of the theoretical predictions and proposed structure of molecules. By using the MM2 program, the optimized structure of the complexes was predicted. Energy optimization was done repeatedly to obtain the minimum energy for the proposed geometry $[47,48]$. The Cd-OTC/Sal and Mo-OTC/Sal metal complexes were reported to have tetrahedral and octahedral geometries with final geometrical energies of 923.1740 and $899.3184 \mathrm{kcal} / \mathrm{mol}$, respectively. By performing the calculation, bonding parameters such as bond length and bond angle with their optimized 3D molecular structures were obtained and are presented in Table S2 and Figures 6 and 7. Through this discussion, the structure of the metal complexes was obtained. The potential energy is the sum of all different types of energy: $E=E_{\text {str }}+E_{\text {bend }}+E_{\text {tor }}+E_{\mathrm{vdw}}+E_{\text {oop }}+E_{\text {ele, }}$ where $E$ 's signify the energy value for many interactions. Similarly, the 
TABLE 1: Kinetic and thermodynamic parameters of the complexes.

\begin{tabular}{lcccccccc}
\hline Compounds & Step & $r$ & $A\left(\mathrm{~s}^{-1}\right)$ & $T_{\max }(\mathrm{K})$ & $E^{*}(\mathrm{~kJ} / \mathrm{mol})$ & $\Delta S^{*}(\mathrm{~J} / \mathrm{k} \cdot \mathrm{mol})$ & $\Delta H^{*}(\mathrm{~kJ} / \mathrm{mol})$ & $\Delta G^{*}(\mathrm{~kJ} / \mathrm{mol})$ \\
\hline \multirow{2}{*}{ Cd-OTC/Sal } & 1 & -0.99562 & 1468.354 & 661.32 & 341.955 & -190.906 & -5156.260 & 121095.353 \\
& 2 & -0.99797 & 220.740 & 934.01 & 168.525 & -209.533 & -7596.834 & 188109.305 \\
\hline \multirow{3}{*}{ Mo-OTC/Sal } & 1 & -0.98404 & 272.996 & 655.49 & 124.544 & -204.823 & -5325.200 & 128934.036 \\
& 2 & -0.99555 & 124.558 & 686.25 & 53.708 & -25.466 & -5651.774 & 11824.561 \\
& 3 & -0.99473 & 230.334 & 763.17 & 131.444 & -207.500 & -6213.551 & 152144.217 \\
\hline
\end{tabular}

Table 2: Thermal decomposition data of the complexes.

\begin{tabular}{lcccccrrr}
\hline \multirow{2}{*}{ Compounds } & \multirow{2}{*}{ Steps } & \multicolumn{3}{c}{ TG range $\left({ }^{\circ} \mathrm{C}\right)$} & \multicolumn{3}{c}{ DTA } \\
& & $\Delta_{m \%}$ found & $T_{i}$ & $T_{f}$ & $T_{\text {DTG }}$ & Mass loss & $T_{\text {dta }}$ & Peak \\
\hline \multirow{2}{*}{ Cd-OTC/Sal } & 1 & 28.01 & 362.05 & 448.12 & 258.18 & -0.837 & 403.75 \\
& 2 & 9.58 & 611.13 & 680.76 & 371.70 & -0.232 & Exo \\
\hline \multirow{3}{*}{ Mo-OTC/Sal } & 1 & 13.022 & 374.30 & 397.33 & 382.34 & -0.742 & 392.96 & Exo \\
& 2 & 17.39 & 407.21 & 417.17 & 413.10 & -0.548 & 415.17 & Exo \\
& 3 & 6.08 & 464.40 & 508.22 & 490.02 & -0.657 & 499.45 & Exo \\
\hline
\end{tabular}

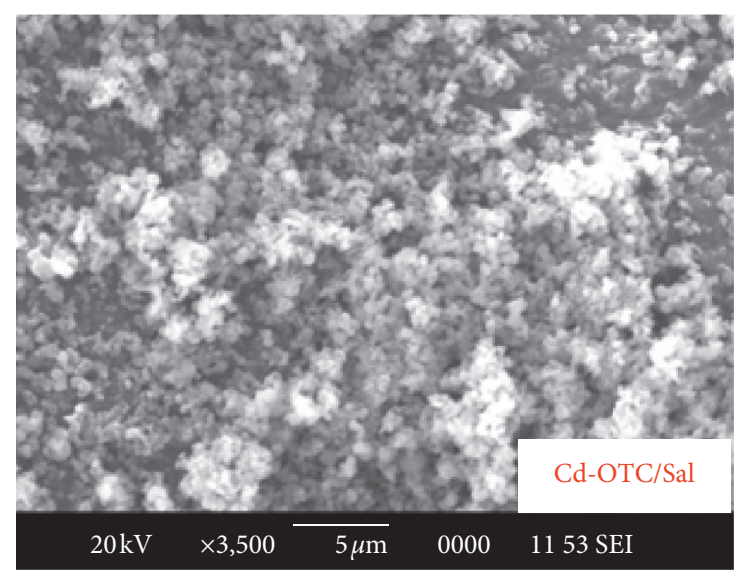

(a)

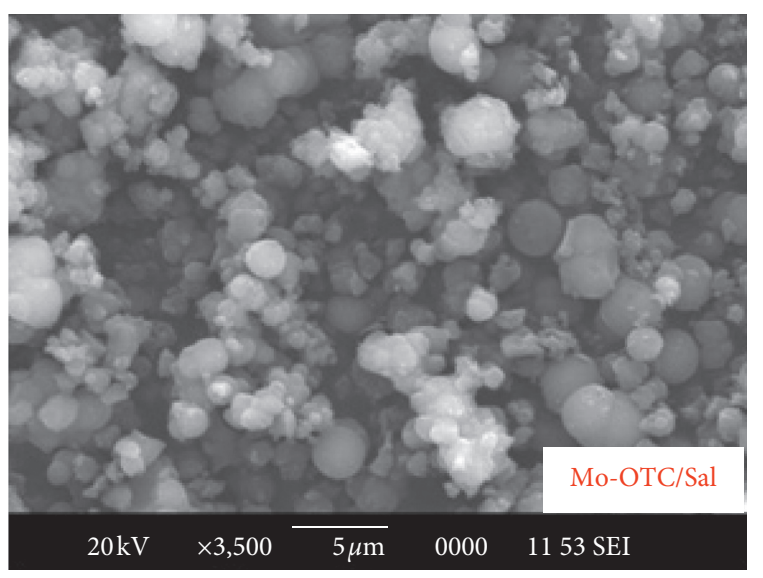

(b)

FIGURE 5: SEM micrograph of the complexes: (a) Cd-OTC/Sal and (b) Mo-OTC/Sal.

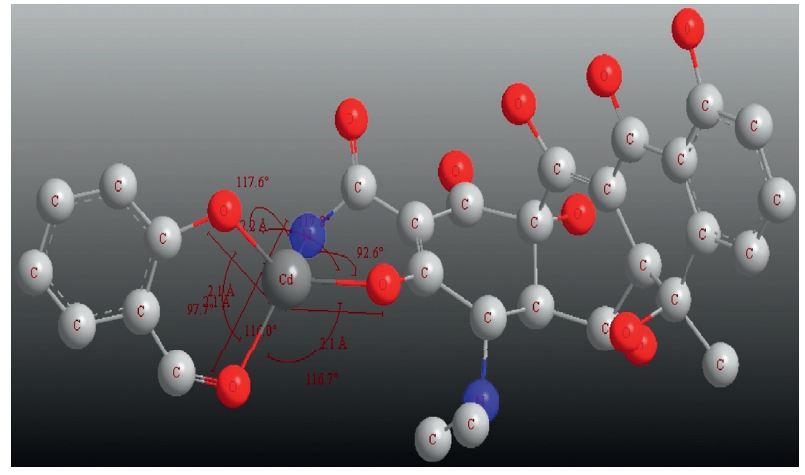

FIgURE 6: Optimized geometry of the Cd-OTC/Sal complex.

subscripts signify the bond stretching, angle bending, deformation angle, van der Waals interactions, out-of-plane bending, simple bending, and electronic interaction, respectively.

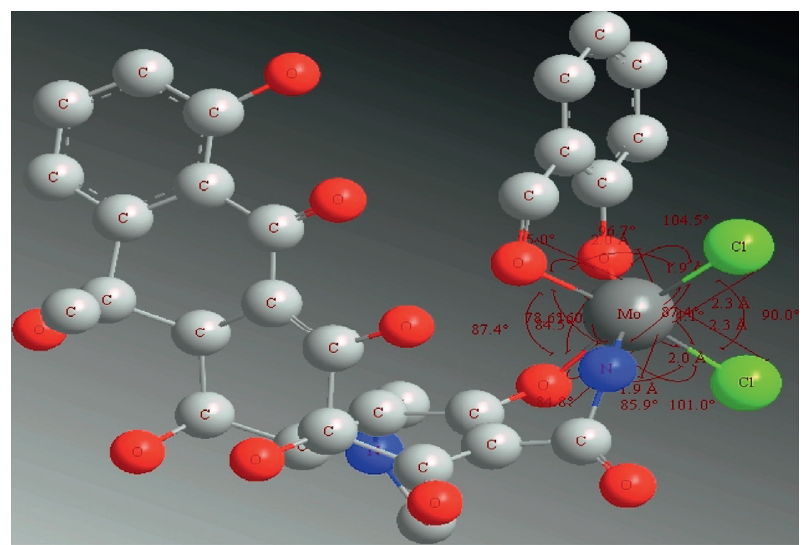

FIgUre 7: Optimized geometry of the Mo-OTC/Sal complex.

3.6. Antibacterial Sensitivity Study. Metal complexes (CdOTC/Sal and Mo-OTC/Sal) were screened for their antimicrobial evaluation using the modified Kirby-Bauer paper 
TABle 3: Antibacterial growth data of Cd-OTC/Sal and Mo-OTC/ Sal metal complexes.

\begin{tabular}{|c|c|c|c|c|c|c|c|c|c|}
\hline \multirow{3}{*}{$\begin{array}{l}\text { Compounds } \\
\text { Concentration }(\mu \mathrm{g} / \mu \mathrm{L})\end{array}$} & \multicolumn{9}{|c|}{ The diameter of zone of inhibition in $\mathrm{mm}$} \\
\hline & \multicolumn{3}{|c|}{ S. aureus } & \multicolumn{3}{|c|}{ P. mirabilis } & \multicolumn{3}{|c|}{ E. coli } \\
\hline & 50 & 25 & 12.5 & 50 & 25 & 12.5 & 50 & 25 & 12.5 \\
\hline $\mathrm{Cd}-\mathrm{OTC} / \mathrm{Sal}$ & 30 & 28 & 26 & 26 & 24 & 21 & 24 & 23 & 20 \\
\hline Mo-OTC/Sal & 18 & 16 & 15 & 24 & 23 & 21 & 23 & 19 & 18 \\
\hline Amikacin $(30 \mu \mathrm{g} /$ disc $)$ & & 21 & & & 21 & & & 14 & \\
\hline OTC (ethanol) & & 37 & & & 33 & & & 28 & \\
\hline OTC (DMSO) & & 41 & & & 34 & & & 29 & \\
\hline
\end{tabular}

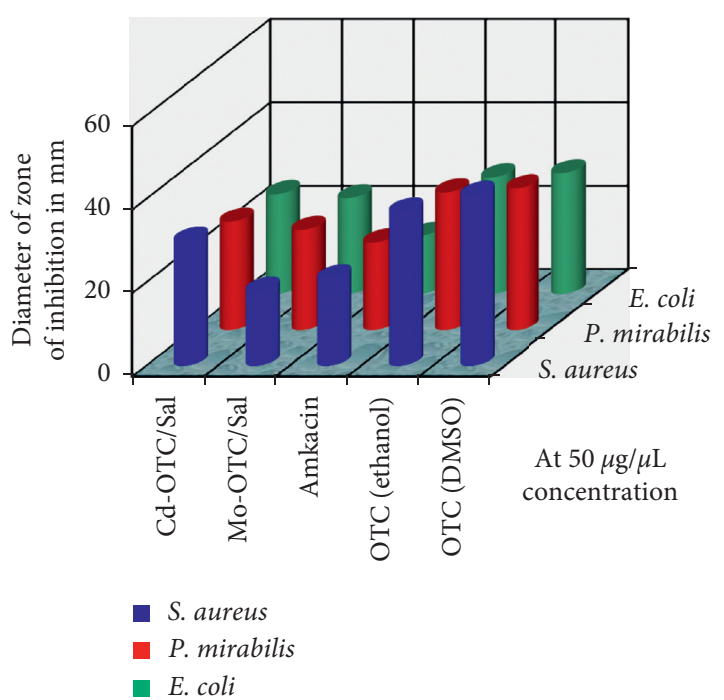

FIGURE 8: Bar graph showing antibacterial sensitivity at $50 \mu \mathrm{g} / \mu \mathrm{L}$ concentration.

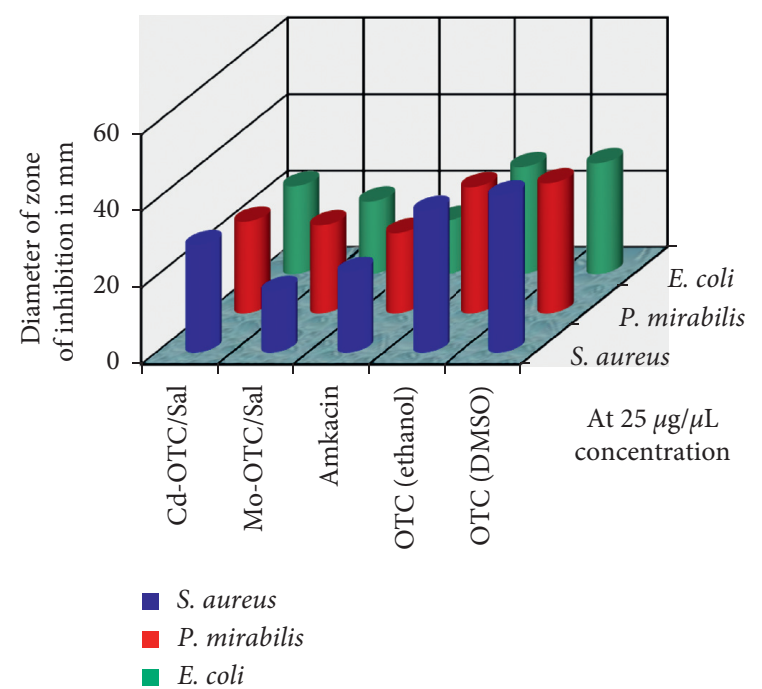

FIGURE 9: Bar graph showing antibacterial sensitivity at $25 \mu \mathrm{g} / \mu \mathrm{L}$ concentration.

disc diffusion technique against $S$. aureus, E. coli, and $P$. mirabilis bacterial pathogens. Three different concentrations $(50,25$, and $12.5 \mu \mathrm{g} / \mu \mathrm{L})$ of the complexes were selected for the study. The growth inhibition data are presented in

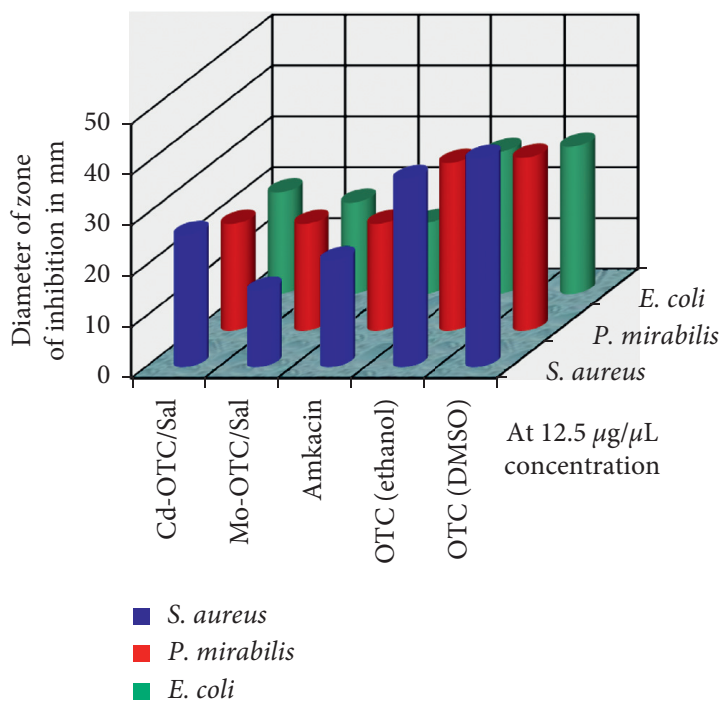

FIGURE 10: Bar graph showing antibacterial sensitivity at $12.5 \mu \mathrm{g} / \mu \mathrm{L}$ concentration.

Table 3, and the pictorial representations are reported in Figures 8-10 and S7. The study revealed considerable antibacterial potency of the complexes with all bacterial pathogens. However, the parent drug oxytetracycline has shown a greater inhibitory effect relative to complexes. Moreover, the growth inhibitory effect is greater at higher concentrations of the complexes $[49,50]$. Antibacterial potency of the complexes is based on the chelation theory. Chelation provides stability of the complex and also provides access for easy permeation of complex through the lipid layer of organisms. This helps in rupturing of the cell wall and deactivates bacterial action.

\section{Conclusions}

In summary, the Cd-OTC/Sal and Mo-OTC/Sal complexes were prepared successfully by coordination of metal ions with oxytetracycline and salicylaldehyde ligands. They were characterized using various spectral and physicochemical techniques. The spectral analysis revealed coordination of metal ions through $\mathrm{O}$ at $\mathrm{C} 3$ and the amide $\mathrm{N}$ atom of $\mathrm{C} 2$ of ring $\mathrm{A}$ of oxytetracycline and $\mathrm{O}$ atoms of salicylaldehydes. The complexes were found as amorphous and colored solids that are insoluble in water but soluble in DMSO and DMF. The electronic absorption data concluded the tetrahedral and octahedral geometries of the Cd-OTC/Sal and Mo-OTC/Sal complexes. This was further supported by molecular modeling studies. Antibacterial studies revealed significant antibiotic action against S.aureus, E.coli, and P. mirabilis bacterial pathogens. The study showed a better antibiotic effect of Cd-OTC/Sal compared to Mo-OTC/Sal.

\section{Data Availability}

The authors share the data underlying the findings of the manuscript. 


\section{Conflicts of Interest}

The authors declare that they have no conflicts of interest.

\section{Acknowledgments}

This research work was fully funded by Nepal Academy of Science and Technology (NAST), Khumaltar, Lalitpur, Nepal, by providing Ph.D. fellowship. Thus, the first author is highly thankful to this organization and the authors also acknowledge SAIF, IIT Bombay; CSIR-CDRI, Lucknow; STIC, Cochin, Kerala; NBU, Siliguri, India, for spectral study.

\section{Supplementary Materials}

Figure S1: FT-IR spectra of Mo-OTC/Sal metal complex. Figure S2: ${ }^{1} \mathrm{H}-\mathrm{NMR}$ spectra of Cd-OTC/Sal metal complex. Figure S3: ${ }^{1} \mathrm{H}-\mathrm{NMR}$ spectrum of Mo-OTC/Sal complex. Figure S4: ESI-MS spectrum of Cd-OTC/Sal complex. Figure S5: electronic absorption spectrum of complexes. Figure S6: thermogram of Cd-OTC/Sal complex. Figure S7: antibacterial activity showing growth inhibition zone around the loaded disc. Table S1: ${ }^{1} \mathrm{H}-\mathrm{NMR}$ spectral data of complexes. Table S2: selected bond length, bond angle, and bond energy of complexes. (Supplementary Materials)

\section{References}

[1] K. L. Haas and K. J. Franz, "Application of metal coordination chemistry to explore and manipulate cell biology," Chemical Reviews, vol. 109, no. 10, pp. 4921-4960, 2009.

[2] A. Frei, J. Zuegg, A. G. Elliott et al., "Metal complexes as a promising source for new antibiotics," Chemical Science, vol. 11, no. 10, pp. 2627-2639, 2020.

[3] T. Jurca, E. Marian, L. G. Vicaş, M. E. Mureşan, and L. Fritea, "Metal complexes of pharmaceutical substances," in Spectroscopic Analyses-Developments and Applications, Wiley, Hoboken, NJ, USA, 2017.

[4] B. D. Nath, K. Takaishi, and T. Ema, "Macrocyclic multinuclear metal complexes acting as catalysts for organic synthesis," Catalysis Science \& Technology, vol. 10, no. 1, pp. 12-34, 2020.

[5] A. S. El-Tabl and S. M. Imam, "New copper (II) complexes produced by the template reaction of acetoacetic-2-pyridyl amide and amino-aliphatic alcohols," Transition Metal Chemistry, vol. 22, no. 3, pp. 259-262, 1997.

[6] J. Bauer, H. Braunschweig, and R. D. Dewhurst, "Metal-only Lewis pairs with transition metal Lewis bases," Chemical Reviews, vol. 112, no. 8, pp. 4329-4346, 2012.

[7] J. Qu, Y. Huang, and X. Lv, "Crisis of antimicrobial resistance in China: now and the future," Frontiers in Microbiology, vol. 10, 2019.

[8] M. Gajdács and F. Albericio, "Antibiotic resistance: from the bench to patients," Antibiotics, vol. 8, no. 3, p. 129, Aug. 2019.

[9] J. Lalucat, M. Mulet, M. Gomila, and E. García-Valdés, "Genomics in bacterial taxonomy: impact on the genus Pseudomonas," Genes, vol. 11, no. 2, p. 139, 2020.

[10] C. S. Allardyce and P. J. Dyson, "Metal-based drugs that break the rules," Dalton Transactions, vol. 45, no. 8, pp. 3201-3209, 2016.
[11] C. F. Markwalter, A. G. Kantor, C. P. Moore, K. A. Richardson, and D. W. Wright, "Inorganic complexes and metal-based nanomaterials for infectious disease diagnostics," Chemical Reviews, vol. 119, no. 2, pp. 1456-1518, 2018.

[12] H. Petković, T. Lukežič, and J. Šušković, "Biosynthesis of oxytetracycline by Streptomyces rimosus: past, present and future directions in the development of tetracycline antibiotics," Food Technology and Biotechnology, vol. 55, no. 1, 2017.

[13] C. Tafalla, B. Novoa, J. M. Alvarez, and A. Figueras, "In vivo and in vitro effect of oxytetracycline treatment on the immune response of turbot, Scophthalmus maximus (L.)," Journal of Fish Diseases, vol. 22, no. 4, pp. 271-276, Jan. 2002.

[14] J. F. Leal, E. B. H. Santos, and V. I. Esteves, "Oxytetracycline in intensive aquaculture: water quality during and after its administration, environmental fate, toxicity and bacterial resistance," Reviews in Aquaculture, vol. 11, no. 4, pp. 1176-1194, 2018.

[15] M. Cherlet, S. De Baere, and P. De Backer, "Quantitative analysis of oxytetracycline and its 4-epimer in calf tissues by high-performance liquid chromatography combined with positive electrospray ionization mass spectrometry," The Analyst, vol. 128, no. 7, p. 871, 2003.

[16] S. Tongaree, D. R. Flanagan, and R. I. Poust, "The interaction between oxytetracycline and divalent metal ions in aqueous and mixed solvent systems," Pharmaceutical Development and Technology, vol. 4, no. 4, pp. 581-591, 1999.

[17] S. Tongaree, A. M. Goldberg, D. R. Flanagan, and R. I. Poust, "The effects of pH and PEG 400-water cosolvents on oxytetracycline-magnesium complex formation and stability," Pharmaceutical Development and Technology, vol. 5, no. 2, pp. 189-199, 2000.

[18] J. M. Wessels, W. E. Ford, W. Szymczak, and S. Schneider, "The complexation of tetracycline and anhydrotetracycline with $\mathrm{Mg}^{2+}$ and $\mathrm{Ca}^{2+}$ : a spectroscopic study," The Journal of Physical Chemistry B, vol. 102, no. 46, pp. 9323-9331, Nov. 1998.

[19] A. Z. El-Sonbati, W. H. Mahmoud, G. G. Mohamed, M. A. Diab, S. M. Morgan, and S. Y. Abbas, "Synthesis, characterization of Schiff base metal complexes and their biological investigation," Applied Organometallic Chemistry, Article ID e5048, 2019.

[20] S. A. Ali, A. A. Soliman, A. H. Marei, and D. H. Nassar, "Synthesis and characterization of new chromium, molybdenum and tungsten complexes of 2-[2-(methylaminoethyl)] pyridine," Spectrochimica Acta Part A: Molecular and Biomolecular Spectroscopy, vol. 94, pp. 164-168, 2012.

[21] R. M. Ahmed, E. I. Yousif, and M. J. Al-Jeboori, "Co(II) and Cd(II) complexes derived from heterocyclic schiff-bases: synthesis, structural characterisation, and biological activity," The Scientific World Journal, vol. 2013, Article ID 754868, 6 pages, 2013.

[22] A. Majumder, G. M. Rosair, A. Mallick, N. Chattopadhyay, and S. Mitra, "Synthesis, structures and fluorescence of nickel, zinc and cadmium complexes with the N,N,O-tridentate Schiff base N-2-pyridylmethylidene-2-hydroxy-phenylamine," Polyhedron, vol. 25, no. 8, pp. 1753-1762, 2006.

[23] A. Golcu, M. Tumer, H. Demirelli, and R. A. Wheatley, "Cd(II) and $\mathrm{Cu}(\mathrm{II})$ complexes of polydentate Schiff base ligands: synthesis, characterization, properties and biological activity," Inorganica Chimica Acta, vol. 358, no. 6, pp. 1785-1797, Mar. 2005.

[24] M. Kalinowska, J. Piekut, A. Bruss et al., "Spectroscopic (FTIR, FT-Raman, 1H, 13C NMR, UV/VIS), thermogravimetric and antimicrobial studies of $\mathrm{Ca}(\mathrm{II}), \mathrm{Mn}(\mathrm{II}), \mathrm{Cu}(\mathrm{II}), \mathrm{Zn}$ (II) and Cd(II) complexes of ferulic acid," Spectrochimica Acta Part A: 
Molecular and Biomolecular Spectroscopy, vol. 122, pp. 631638, Mar. 2014.

[25] J. dos Santos Ferreira da Silva, D. López Malo, G. Anceski Bataglion et al., "Adsorption in a fixed-bed column and stability of the antibiotic oxytetracycline supported on $\mathrm{Zn}$ (II)[2-Methylimidazolate] frameworks in aqueous media," PLoS One, vol. 10, no. 6, Article ID e0128436, 2015.

[26] S. Gupta, A. K. Barik, S. Pal et al., "Oxomolybdenum(VI) and (IV) complexes of pyrazole derived ONO donor ligands-synthesis, crystal structure studies and spectroelectrochemical correlation," Polyhedron, vol. 26, no. 1, pp. 133-141, 2007.

[27] S. H. Tarulli, O. V. Quinzani, E. J. Baran, O. E. Piro, and E. E. Castellano, "Structural and spectroscopic characterization of two new Cd(II) complexes: bis(thiosaccharinato) bis(imidazole) cadmium(II) and tris(thiosaccharinato)aquacadmate(II)," Journal of Molecular Structure, vol. 656, no. 1-3, pp. 161-168, Aug. 2003.

[28] G. More, D. Raut, K. Aruna, and S. Bootwala, "Synthesis, spectroscopic characterization and antimicrobial activity evaluation of new tridentate Schiff bases and their $\mathrm{Co}$ (II) complexes," Journal of Saudi Chemical Society, vol. 21, no. 8, pp. 954-964, 2017.

[29] S. Nzikayel, I. J. Akpan, and E. C. Adams, "Synthesis, FTIR and electronic spectra studies of metal (II) complexes of pyrazine-2-carboxylic acid derivative," Medicinal Chemistry, vol. 7, no. 11, 2017.

[30] M. M. Omar, H. F. Abd El-Halim, and E. A. M. Khalil, "Synthesis, characterization, and biological and anticancer studies of mixed ligand complexes with Schiff base and 2,2'bipyridine," Applied Organometallic Chemistry, vol. 31, no. 10, Article ID e3724, 2017.

[31] D. Kumar, S. Chadda, J. Sharma, and P. Surain, "Syntheses, spectral characterization, and antimicrobial studies on the coordination compounds of metal ions with schiff base containing both aliphatic and aromatic hydrazide moieties," Bioinorganic Chemistry and Applications, vol. 2013, Article ID 981764, 10 pages, 2013.

[32] O. A. M. Ali, "Synthesis, spectroscopic, fluorescence properties and biological evaluation of novel Pd(II) and Cd(II) complexes of NOON tetradentate Schiff bases," Spectrochimica Acta Part A: Molecular and Biomolecular Spectroscopy, vol. 121, pp. 188-195, Mar. 2014.

[33] M. H. A. Al-Amery, "Synthesis, Characterization and antibacterial studies of mixed ligand complexes of 2- phenyl-2-(otolylamino) acetonitrile and 1,10-phenanthroline with some metal ions," Der Pharma Chemica, vol. 9, pp. 59-69, 2017.

[34] S. Pasayat, S. P. Dash, Saswati et al., "Mixed-ligand aroylhydrazone complexes of molybdenum: synthesis, structure and biological activity," Polyhedron, vol. 38, no. 1, pp. 198-204, 2012.

[35] M. Bagherzadeh, M. Amini, A. Ellern, and L. K. Woo, "Catalytic efficiency of a novel complex of oxoperoxo molybdenum (VI): synthesis, X-ray structure and alkane oxidation," Inorganic Chemistry Communications, vol. 15, pp. 52-55, 2012.

[36] A. M. Kamel, P. R. Brown, and B. Munson, "Electrospray ionization mass spectrometry of tetracycline, oxytetracycline, chlorotetracycline, minocycline, and methacycline," Analytical Chemistry, vol. 71, no. 5, pp. 968-977, Mar. 1999.

[37] R. Gomathi, A. Ramu, and A. Murugan, "Evaluation of DNA binding, cleavage, and cytotoxic activity of $\mathrm{Cu}(\mathrm{II}), \mathrm{Co}(\mathrm{II})$, and $\mathrm{Ni}$ (II) schiff base complexes of 1-phenylindoline-2,3-dione with isonicotinohydrazide," Bioinorganic Chemistry and Applications, vol. 2014, Article ID 215392, 12 pages, 2014.

[38] S. A. Shaker, "Preparation and spectral properties of mixedligand complexes of $\mathrm{VO}(\mathrm{IV}), \mathrm{Ni}(\mathrm{II}), \mathrm{Zn}(\mathrm{II}), \mathrm{Pd}(\mathrm{II}), \mathrm{Cd}(\mathrm{II})$ and $\mathrm{Pb}$ (II) with dimethylglyoxime andN-acetylglycine," E-Journal of Chemistry, vol. 7, no. 1, pp. S580-S586, 2010.

[39] A. Ahmed and R. A. Lal, "Synthesis and electrochemical characterisation of molybdenum(VI) complexes of disalicylaldehyde malonoyl-dihydrazone," Journal of Molecular Structure, vol. 1048, pp. 321-330, 2013.

[40] M. M. H. Khalil and F. A. Al-Seif, "Molybdenum and tungsten tricarbonyl complexes of isatin with triphenylphosphine," Research Letters in Inorganic Chemistry, vol. 2008, Article ID 746058, 4 pages, 2008.

[41] M. Saif, M. M. Mashaly, M. F. Eid, and R. Fouad, "Synthesis, characterization and thermal studies of binary and/or mixed ligand complexes of $\mathrm{Cd}(\mathrm{II}), \mathrm{Cu}(\mathrm{II}), \mathrm{Ni}(\mathrm{II})$ and $\mathrm{Co}(\mathrm{III})$ based on 2-(Hydroxybenzylidene) thiosemicarbazone: DNA binding affinity of binary $\mathrm{Cu}(\mathrm{II})$ complex," Spectrochimica Acta Part A: Molecular and Biomolecular Spectroscopy, vol. 92, pp. 347-356, 2012.

[42] P. Cervini, B. Ambrozini, L. C. M. Machado, A. P. G. Ferreira, and É and ra Cavalheiro, "Thermal behavior and decomposition of oxytetracycline hydrochloride," Journal of Thermal Analysis and Calorimetry, vol. 121, no. 1, pp. 347-352, 2015.

[43] S. Ramotowska, M. Wysocka, J. Brzeski, A. Chylewska, and M. Makowski, "A comprehensive approach to the analysis of antibiotic-metal complexes," TrAC Trends in Analytical Chemistry, vol. 123, p. 115771, 2020.

[44] R. Gaur and P. Jeevanandam, "Effect of anions on the morphology of CdS nanoparticles prepared via thermal decomposition of different cadmium thiourea complexes in a solvent and in the solid state," New Journal of Chemistry, vol. 39, no. 12, pp. 9442-9453, 2015.

[45] X. Chen, J. Qi, P. Wang, C. Li, X. Chen, and C. Liang, "Polyvinyl alcohol protected $\mathrm{Mo}_{2} \mathrm{C} / \mathrm{Mo}_{2} \mathrm{~N}$ multicomponent electrocatalysts with controlled morphology for hydrogen evolution reaction in acid and alkaline medium," Electrochimica Acta, vol. 273, pp. 239-247, 2018.

[46] F. Chen, X. Zou, C. Chen et al., "Surfactant-free synthesis of homogeneous nano-grade cadmium sulfide grafted reduced graphene oxide composite as a high-activity photocatalyst in visible light," Ceramics International, vol. 45, no. 11, pp. 14376-14383, 2019.

[47] B. B. Mahapatra, R. R. Mishra, and A. K. Sarangi, "Synthesis, spectral, thermogravimetric, $\mathrm{XRD}$, molecular modelling and potential antibacterial studies of dimeric complexes with bis bidentate ON-NO donor Azo dye ligands," Journal of Chemistry, vol. 2013, Article ID 653540, 11 pages, 2013.

[48] P. Mishra, "Biocoordination and computational modeling of novel ligands with $\mathrm{Bi}(\mathrm{V})$," International Journal of Chem Tech Research, vol. 1, no. 3, pp. 401-419, 2009.

[49] S. A. Mousavi, M. Montazerozohori, R. Naghiha, A. Masoudiasl, S. Mojahedi, and T. Doert, "Some novel hexa-coordinated cadmium Schiff base complexes: X-ray structure, Hirshfeld surface analysis, antimicrobial and thermal analysis," Applied Organometallic Chemistry, vol. 34, no. 4, Article ID e5048, 2020.

[50] L. Tabrizi, P. McArdle, M. Ektefan, and H. Chiniforoshan, "Synthesis, crystal structure, spectroscopic and biological properties of mixed ligand complexes of cadmium(II), cobalt(II) and manganese(II) valproate with 1,10-phenanthroline and imidazole," Inorganica Chimica Acta, vol. 439, pp. 138-144, 2016. 